\title{
THE AGGLUTINATING PROPERTIES OF EXUDATES FROM PATIENTS WITH RHEUMATIC FEVER
}

\author{
BY CHARLES H. HITCHCOCK AND HOMER F. SWIFT
}

\author{
(From the Hospital of the Rockefeller Institute for Medical Research, New York, \\ and the Department of Bacteriology, University of Pennsylvania \\ School of Medicine, Philadelphia)
}

(Received for publication February 23, 1933)

Recent reports $(1,2,3)$ that serum from febrile patients and exudates from tuberculous pleurae exert an apparently non-specific agglutinating effect upon certain gram-positive cocci have prompted the publication of similar results concerning the properties of exudates obtained from patients suffering from various acute manifestations of rheumatic fever.

During the course of a search for agglutinins and precipitins in the body fluids of such patients, it was observed that exudate obtained from the knee during the course of an acute arthritis possessed a marked capacity to cause flocculent growth (thread reaction) of a certain strain of Streptococcus haemolyticus. This strain, "S43 matt avirulent," had been kept in the laboratory for many years upon artificial media. So striking was this effect, noted at times even in a dilution of $1: 10,000$ of the exudate, that it seemed desirable to extend the observations to other organisms, as well as to include exudates from conditions other than rheumatic fever.

\section{METHODS}

The ease and convenience with which the thread reaction can be set up and read depends, in no small measure, upon the size of the tube and its relation to the amount of liquid contained therein. After several trials, it was found that a total volume of $2 \mathrm{cc}$. in a tube of about $12 \mathrm{~mm}$. internal diameter was satisfactory. Serial dilutions of serum or of exudate were made in plain buffered infusion broth, $\mathrm{pH}$ 7.8. Separate pipettes were used for each dilution; this is highly important in the case of rheumatic exudates, because of their great viscosity. Ordinarily four tubes were set up for each test, containing dilutions varying from $1: 10$ to $1: 10,000$. The blood serum of the patient furnishing the exudate was used as a control; frequently both exudate and blood were obtained on the same day. Additional controls consisted of serum from healthy individuals, and also of plain broth containing no protein. All tubes were seeded with 20-hour broth cultures-streptococci in dosage of 0.005 cc., staphylococci and $B$. coli in $0.002 \mathrm{cc}$. amounts. Readings were made after incubation at $37^{\circ} \mathrm{C}$. for 24 hours, and were usually repeated after a further 24 hours at room 
temperature. Inasmuch as most of the organisms, including the streptococci, grew diffusely under these conditions, it was found possible to record results with a system of plus signs, as for agglutination readings; thus ++++ was used to indicate a completely sedimented growth, and a clear supernatant liquid; occasionally a filmy clot was produced, due to an excess of fibrin. Varying degrees of sedimentation with diffuse clouding of the supernatant fluid were indicated by,,++++++ and \pm .

In Table $I$ is presented a summary of the strains employed. In addition, one or two tests each were made with $H$. influenzae, pneumococcus Type $I$, and an $R$ strain of pneumococcus.

TABLE I

Strains employed for thread reactions

\begin{tabular}{l|c|l|l}
\hline \multicolumn{1}{c|}{ Strain } & Generation & \multicolumn{1}{|c}{ Organism } & \multicolumn{1}{|c}{ Source } \\
\hline S43 & Unknown & Streptococcus haemolyticus & Laboratory; matt avirulent \\
N80 & 4 & Streptococcus haemolyticus & Blood, ? (Viertel) \\
N60 & 5 & Streptococcus haemolyticus & Throat, rheumatic fever \\
N49 & 3,4 & Streptococcus haemolyticus & Sputum, rheumatic pneumonitis \\
S23 & Unknown & Streptococcus haemolyticus & Laboratory; glossy variant \\
N69 & 4,5 & Streptococcus haemolyticus & Throat, rheumatic fever \\
N108 & 4,5 & Streptococcus haemolyticus & Throat, rheumatic fever \\
N82 & 3,4 & Streptococcus haemolyticus & Tonsil at operation, rheumatic fever \\
N105 & 5,6 & Streptococcus haemolyticus & Throat, rheumatic fever \\
N83 & 4 & Streptococcus haemolyticus & Tonsil at operation, rheumatic fever \\
N92 & 3,4 & Streptococcus haemolyticus & Throat, rheumatic fever \\
Staph. R & Unknown & Staphylococcus aureus & Laboratory strain \\
N20 & 3,4 & Staphylococcus aureus & Nose, subacute ethmoiditis \\
N72 & 3 & Staphylococcus albus & Ethmoid, rheumatic fever \\
N99 & 3 & Staphylococcus aureus & Ethmoid, rheumatic fever \\
N127 & 3,4 & Staphylococcus ? & Throat, rheumatic fever \\
A84 & 12 & Streptococcus viridans & Blood, endocarditis lenta \\
A49 & 34,35 & Streptococcus viridans & Blood, rheumatic fever \\
N32B & 4,5 & Streptococcus viridans & Blood, rheumatic fever \\
Q155 & 8,9 & Streptococcus indifferens & Throat, rheumatic fever \\
R1 & Unknown & Streptococcus indifferens & Blood, rheumatic fever \\
N29A & 4,5 & Streptococcus indifferens & Blood, rheumatic fever \\
N37D & $3,4,5$ & Diphtheroid & Joint exudate, rheumatic fever \\
N59C & $3,4,5$ & Diphtheroid & (contamination ?) \\
N81 & Unknown & Gram-negative coccus & Blood, rheumatic fever \\
B. Coli & Unknown & & Normal throat \\
& & & Laboratory strain \\
\hline & & & \\
\hline
\end{tabular}

RESULTS

In all, thirty exudates from fourteen rheumatic fever patients were studied; of these, five were pleural fluids, one was a pericardial exudate, while the remainder were obtained from acutely inflamed knees. In addition, observations were made upon nine fluids from as many patients suffering from exudative conditions other than rheumatic fever. These included pleural effusion (tuberculous), prepatellar bursitis, gonorrheal 


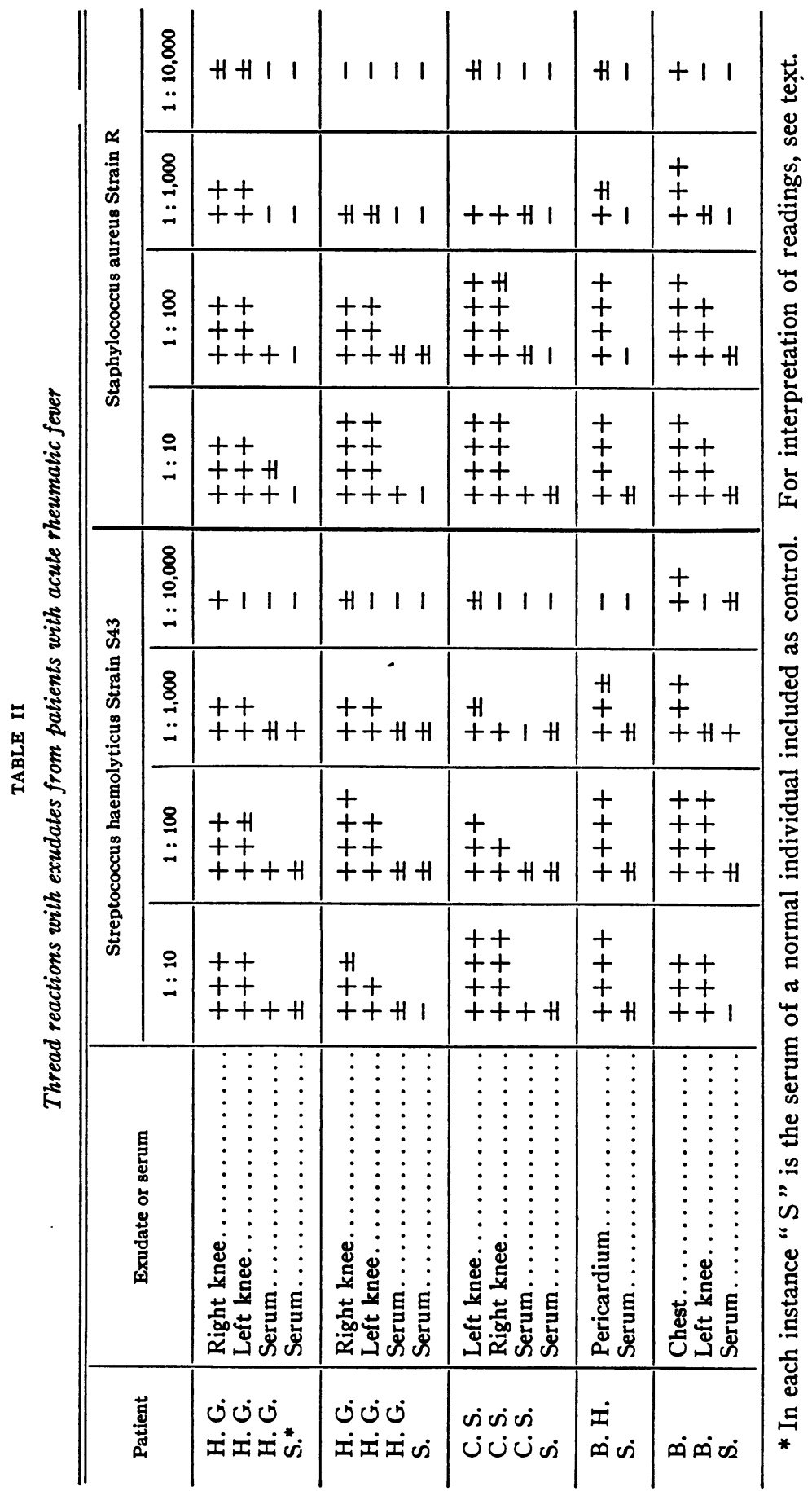


arthritis, tuberculous arthritis, acute synovitis, chronic infectious arthritis, villous synovitis and fracture into the knee joint.

In Table II are presented a few typical protocols. It will be noted that in dilutions of $1: 1,000$ these exudates were capable of causing well marked agglutinated growth of old laboratory strains of Streptococcus haemolyticus and Staphylococcus aureus. Pleural and pericardial effusions were generally somewhat more active than articular exudates. In tests with the former it was noted, in the first tube especially, that firmly matted growth usually occurred, frequently with the formation of a filmy clot in the supernatant liquid. Not all synovial fluids, however, possessed the same capacity to induce agglutinated growth. None was ever devoid of effect, but, of the twenty-four, six were no more active than were exudates from non-rheumatic patients. No explanation for this variability in freshly drawn fluids has been forthcoming. Certain fluctuations in the degree of effectiveness were noted upon retesting the same specimen from time to time. This apparently resulted from slight differences in the agglutinability of individual daily cultures, inasmuch as a distinct decrease in the activity of the exudates themselves could not be surely demonstrated until after the lapse of several weeks or months.

In Table III are presented the results obtained with fluids from 9 nonrheumatic patients. It will be noted that a slight or very moderate effect

TABLE III

Thread reactions with exudates from non-rheumatic patients

\begin{tabular}{|c|c|c|c|c|c|c|c|c|c|}
\hline \multirow{2}{*}{ Patient } & \multirow{2}{*}{ Condition } & \multicolumn{4}{|c|}{$\begin{array}{l}\text { Streptococcus haemolyticus } \\
\text { Strain S43 }\end{array}$} & \multicolumn{4}{|c|}{$\begin{array}{l}\text { Staphylococcus aureus } \\
\text { Strain R }\end{array}$} \\
\hline & & $1: 10$ & $1: 100$ & $1: 1,000$ & $1: 10,000$ & $1: 10$ & $1: 100$ & $1: 1,000$ & $1: 10,000$ \\
\hline $\begin{array}{l}\text { Bl. } \\
\text { B. } \\
\text { P. } \\
\text { S. } \\
\text { P. } \\
\text { B. } \\
\text { S. } \\
\text { S. } \\
\text { R. }\end{array}$ & $\begin{array}{l}\text { Tuberculous } \\
\text { pleurisy....... } \\
\text { Prepatellar } \\
\text { bursitis....... } \\
\text { Gonorrheal } \\
\text { arthritis...... } \\
\text { Tuberculous } \\
\text { arthritis...... } \\
\text { Acute synovitis.. } \\
\text { Acute synovitis.. } \\
\text { Chronic infectious } \\
\text { arthritis...... } \\
\text { Villous synovitis. } \\
\text { Fracture into } \\
\text { knee joint..... }\end{array}$ & $\begin{array}{l}\text { N.G.* } \\
+ \\
\pm \\
\pm \\
++ \\
\pm \\
- \\
\pm \\
\pm\end{array}$ & $\begin{array}{l}- \\
+ \\
++ \\
++ \pm \\
++ \\
+ \\
\pm \\
+ \pm \\
++\end{array}$ & $\begin{array}{l}- \\
+ \\
++ \\
+ \pm \\
\pm \\
\pm \\
\pm \\
\pm \\
\pm\end{array}$ & $\begin{array}{l}- \\
\pm \\
- \\
- \\
- \\
- \\
-\end{array}$ & $\begin{array}{l}++ \\
+ \\
++ \\
++ \\
++ \\
+ \pm \\
+ \pm \\
++ \\
+++\end{array}$ & $\begin{array}{l}+ \\
+ \\
++ \\
+ \pm \\
+ \pm \\
++ \\
+ \\
++ \\
+ \pm\end{array}$ & $\begin{array}{l}+ \\
? \\
+ \\
\pm \\
+ \\
+ \\
\pm \\
\pm \\
\pm\end{array}$ & $\begin{array}{l}- \\
- \\
\pm \\
- \\
+\dagger \\
\pm \\
- \\
- \\
-\end{array}$ \\
\hline
\end{tabular}

* No growth.

† On this occasion control broth tube showed \pm sedimentation. 
was produced by each, but that none approached the exudate from acute rheumatic joints in capacity to induce threading. However, as noted above, occasionally an exudate from a rheumatic subject was found to be no more active than other fluids. No correlation was found between total cell count and agglutinating activity of the fluids.

Comparative tests with other micro-organisms disclosed that, of those used, staphylococci and hemolytic streptococci alone gave a distinct thread reaction when grown in exudates, and among these the two old laboratory strains gave the best reactions. Six strains of non-hemolytic streptococci, two diphtheroid strains, a gram-negative coccus, $B$. coli, $H$. influenzae, pneumococcus Type I and pneumococcus $R$ were tested with sufficient frequency against active exudates to demonstrate that agglutinated growth was no more marked and occurred to no higher titer in the presence of these exudates than in control tests employing blood serum from patients or from normal individuals. Of ten additional strains of Streptococcus haemolyticus, none showed more than traces of susceptibility. Among four additional strains of staphylococci, one only was acted upon, and this but to a moderate degree. It will be noted from Table I that, with the exception of the glossy variant of streptococcus S23, none of these relatively poorly reacting hemolytic streptococci was more than six culture generations removed from original isolation. It is quite possible that repeated transfer on artificial media may, without leading to antigenic degradation, have eventually brought about an alteration in surface properties revealed by susceptibility to the agglutinative properties of the exudates.

At no time was any patient's serum found to cause sedimented growth of Streptococcus haemolyticus more markedly than a control normal serum, although bleedings were frequently made upon days when highly active exudates were obtained. Against Staphylococcus aureus such sera frequently showed a slightly increased activity, as compared with normal sera. This may be explained by the observation that Staphylococcus aureus was usually a better detector for the phenomenon, inasmuch as the agglutinative effect of the exudates was often more marked against this organism. Never, however, was the effect of serum at all comparable with that of an exudate. A few illustrations of this fact are presented in Table IV.

Heating of active exudates at $56^{\circ} \mathrm{C}$. for 30 minutes regularly resulted in marked diminution of activity, though at no time was this completely destroyed. Sample protocols are collected in Table V. Efforts to restore the activity by the use of pooled human or guinea pig complement in $1: 20$ dilution were at best equivocal, and usually obviously unsuccessful. Such apparent restoration as occurred was shown by control tests to be traceable to the tendency of the fresh serum to increase the granularity of growth of the organism. 


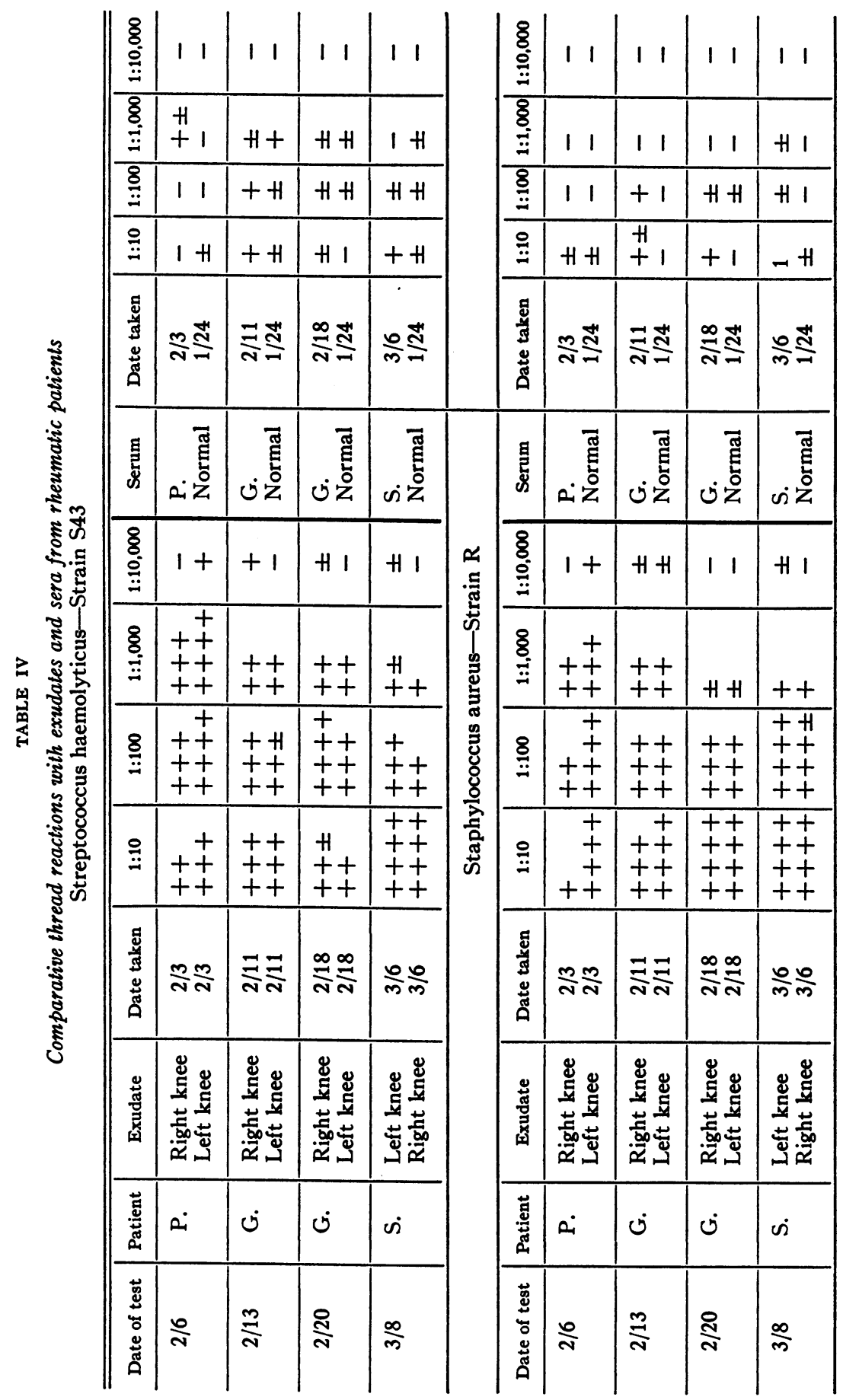


TABLE V

Effect of heat upon thread reactions with exudates

Streptococcus haemolyticus-Strain S43

\begin{tabular}{|c|c|c|c|c|c|c|c|c|c|}
\hline \multirow{2}{*}{ Patient } & \multirow{2}{*}{ Exudate } & \multicolumn{4}{|c|}{ Unheated } & \multicolumn{4}{|c|}{ Heated 30 minutes at $56^{\circ} \mathrm{C}}$. \\
\hline & & $1: 10$ & $1: 100$ & $1: 1,000$ & $1: 10,000$ & $1: 10$ & $1: 100$ & $1: 1,000$ & $1: 10,000$ \\
\hline $\begin{array}{l}\text { G. } \\
\text { F. } \\
\text { F. } \\
\text { S. } \\
\text { S. } \\
\text { B.H. }\end{array}$ & $\begin{array}{l}\text { Right knee.. } \\
\text { Chest } 1 . . . . \\
\text { Chest } 2 \ldots \\
\text { Left knee. . . . } \\
\text { Right knee. . } \\
\text { Pericardium. }\end{array}$ & $\begin{array}{l}+t \\
+t \\
+ \pm \\
+t+t \\
++t+ \\
+t+t\end{array}$ & $\begin{array}{l}+t+ \\
+t+ \\
++t \\
++t+ \\
+t \\
+t+t\end{array}$ & $\begin{array}{l} \pm \\
t+ \pm \\
t+ \\
t \pm \\
t \\
t+ \pm\end{array}$ & $\begin{array}{l}- \\
\pm \\
- \\
\pm \\
-\end{array}$ & $\begin{array}{l}+ \\
+ \\
\pm \\
+ \\
+ \\
+t\end{array}$ & $\begin{array}{l}+ \pm \\
\pm \\
\pm \\
+ \\
+t \\
++\end{array}$ & $\begin{array}{l}- \\
- \\
\pm \\
\pm \\
\pm \\
+ \pm\end{array}$ & $\begin{array}{l}- \\
- \\
- \\
-\end{array}$ \\
\hline
\end{tabular}

Staphylococcus aureus-Strain $\mathbf{R}$

\begin{tabular}{|c|c|c|c|c|c|c|c|c|c|}
\hline \multirow{2}{*}{ Patient } & \multirow{2}{*}{ Exudate } & \multicolumn{4}{|c|}{ Unheated } & \multicolumn{4}{|c|}{ Heated 30 minutes at $56^{\circ} \mathrm{C}$. } \\
\hline & & $1: 10$ & $1: 100$ & $1: 1,000$ & $1: 10,000$ & $1: 10$ & $|1: 100|$ & $1: 1,000$ & $1: 10,000$ \\
\hline $\begin{array}{l}\text { G. } \\
\text { F. } \\
\text { F. } \\
\text { S. } \\
\text { S. } \\
\text { B.H. }\end{array}$ & $\begin{array}{l}\text { Right knee. . } \\
\text { Chest } 1 \ldots . . . \\
\text { Chest } 2 \ldots . . . \\
\text { Left knee. . . } \\
\text { Right knee. . } \\
\text { Pericardium. }\end{array}$ & $\begin{array}{l}+t \\
+t+t \\
++t \\
++t+ \\
+++t \\
+t+t\end{array}$ & $\begin{array}{l}+ \\
++t \\
+t \\
+++t \\
+++t \\
+t+t\end{array}$ & $\begin{array}{l} \pm \\
+ \pm \\
+ \\
+ \\
+ \\
+ \pm\end{array}$ & $\begin{array}{l}- \\
\pm \\
- \\
\pm \\
- \\
\pm\end{array}$ & $\begin{array}{l}t+ \\
\pm \\
+ \\
+ \pm \\
+ \pm \\
t+\end{array}$ & $\begin{array}{l}+ \\
\pm \\
+ \\
+ \\
+ \\
++\end{array}$ & $\begin{array}{l} \pm \\
- \\
+ \\
\pm \\
- \\
\pm\end{array}$ & $\begin{array}{l}- \\
- \\
- \\
-\end{array}$ \\
\hline
\end{tabular}

\section{DISCUSSION}

Clumping of streptococci in sera from patients suffering from disease not necessarily due to these micro-organisms has been carefully studied by Tillett and Abernethy (1). These authors have demonstrated that the reactive body is not potent against freshly isolated strains, but that after repeated subculture upon artificial media the organisms become susceptible to this kind of agglutination. Heating of the organisms to their thermal death point renders them inagglutinable, whereas treatment with formalin does not. Furthermore, the active principle may be precipitated from diluted serum by saturation with carbon dioxide, whereas " true" antibody (antityphosus agglutinin) remains in solution. This accords well with the observations of Morton (3), that ammonium sulphate in 0.75 molar concentration precipitates from pleural fluid of tuberculous patients the substance responsible for "agglutination" of Staphylococcus aureus (2). Hitchcock (4) has found in the past that sera from patients convalescent from lobar pneumonia exert a definite clumping action upon indifferent streptococci, and that this action reaches a maximum about ten days after the crisis. Reimann (5) and Weaver (6) have published observations bearing upon non-specific clumping of bacteria under somewhat comparable conditions. 
The studies herein presented demonstrate that acute inflammatory exudates possess properties similar to those of sera from febrile patients. Quantitative comparisons are not possible, inasmuch as there is as yet no method for standardization of strain susceptibility to the phenomenon. The fact, however, that in the present study sera, taken during the acute manifestations of rheumatism, have failed to act more than slightly upon the strains employed suggests that these sera were less well suited to the study of the reaction than were Tillett's. This would imply a higher reactivity in exudates than in sera. On the other hand, one is not completely justified in drawing parallels between agglutination and the thread reaction. Whereas in the case of true antibody the two tests yield comparable results and the thread reaction is more sensitive, there is no guarantee that this will hold when factors more labile than agglutinins are studied. It is possible, therefore, that the prolonged incubation at $37^{\circ} \mathrm{C}$. necessary for the demonstration of the thread reaction may of itself destroy some of the substances responsible for inducing the phenomenon. Certainly, there is a marked difference between the stability of this factor at $56^{\circ} \mathrm{C}$. and that of a true antibody. Unfortunately, by using fresh exudates from rheumatic joints, rich in fibrinogen, agglutination reactions with the strains employed in the present study have been unsatisfactory. The organisms clumped slowly, so that, by the time the tubes were ready for reading, small fibrin clots had formed, particularly in the lower dilutions. This clot formation has not interfered with the reading of the thread reaction, inasmuch as the organisms have shown no tendency to grow up through the fibrin mesh.

It is idle to speculate whether the same mechanism has been at work in the various studies cited. The fact, however, that according to the experience of others an apparently comparable material is heat labile and is precipitated by $\mathrm{CO}_{2}$ and by weak solutions of ammonium sulfate suggests that it is associated with a globulin similar to fibrinogen.

\section{CONCLUSIONS}

Joint, pleural and pericardial exudates from patients with rheumatic fever cause clumped growth of certain strains of hemolytic streptococci and staphylococci, when tested by the thread reaction. Certain other varieties of bacteria are unaffected. This property is possessed in lesser degree by exudates from non-rheumatic patients.

Old laboratory strains are suitable for demonstration of the reaction; while freshly isolated strains are usually unsuitable.

The active material is greatly reduced in potency by heating at $56^{\circ} \mathrm{C}$. It is not reactivated by the addition of complement.

These observations have no necessary bearing upon the question of the etiology of rheumatic fever. 


\section{BIBLIOGRAPHY}

1. Tillett, W. S., and Abernethy, T. J., Bull. Johns Hopkins Hosp., 1932, 1, 270. Serological Reactions with Hemolytic Streptococci in Acute Bacterial Infections.

2. Pinner, M., and Voldrich, M., J. Infect. Dis., 1932, 1, 143. Staphylococcus Aureus Agglutinins in Tuberculous Effusions.

3. Morton, H. E., personal communication.

4. Hitchcock, C. H., unpublished observations.

5. Reimann, H. A., Ann. Int. Med., 1932, vi, 362. The Significance of Fever and Blood Protein Changes in regard to Defense against Infection.

6. Weaver, G. H., J. Infect. Dis., 1904, i, 91. Agglutination of Streptococci, especially Those Cultivated from Cases of Scarlatina, by Human Sera. 